\title{
Uma nova espécie de Charidotis Boheman de Terenos, Mato Grosso do Sul, Brasil (Coleoptera, Chrysomelidae, Cassidinae) ${ }^{1}$
}

Zundir José Buzzi ${ }^{2}$

\begin{abstract}
A new species of Charidotis Boheman from Terenos, Mato Grosso do Sul, Brazil (Coleoptera, Chrysomelidae, Cassidinae). Charidotis terenosensis sp. n., a new species from Terenos, Mato Grosso do Sul, Brazil, is described. KEY WORDS. Coleoptera, Chrysomelidae, Cassidinae, Charidotis, new species
\end{abstract}

O gênero Charidotis foi erigido por BoHEMAN (1855) com 45 espécies. SPAETH $(1914,1936)$ descreveu inúmeras espécies. No catálogo de BLACKWELDER (1946) estão relacionadas 170 espécies.

Exemplares de uma nova espécie de Charidotis me foram enviados pelo Dr. Wilson W. Koller, Empresa Brasileira de Pesquisa Agropecuária (Embrapa), Campo Grande, Centro Nacional de Pesquisa de Gado de Corte e que foram coletados alimentando-se sobre Memora peregrina (Miers) Sandwith. (Bignoniaceae), comumente conhecida como ciganinha, uma planta nativa da flora do cerrado e que se tornou invasora de pastagens cultivadas.

Todas as medidas são dadas em milímetros.

\section{Charidotis terenosensis sp. $\mathbf{n}$.}

Em vista dorsal (Fig. 1), subarredondada, cerca de 1,11 vezes mais longa que sua maior largura $(5,25 \times 4,75)$; em vista lateral (Fig. 2) com forte curvatura dorsal, mais suave do meio para frente e para traz, decaindo rapidamente; na altura do escutelo com depressão que atinge também a parte posterior mediana do pronoto.

Coloração amarelo-pálido. Dorsalmente com um anel marron-escuro, às vezes, avermelhado, de bordos irregulares, que abrange a parte posterior do pronoto, escutelo e élitros onde não alcança o bordo discal; incluso no anel, uma mancha amarela, com pequenas manchas da mesma cor do anel, às vezes, situadas somente no fundo dos pontos.

Cabeça com sulco, desde a área interalveolar até o vértice, anteriormente, onde estão dois pequenos tubérculos. Fronte lisa, pouco mais larga que longa $(0,40$ $\mathrm{x} 0,30$ ). Antenas alcançando o bordo pronotal; os cinco artículos basais pouco mais brilhantes que os demais, pilosos. Os artículos medindo respectivamente do primeiro ao último: $0,26-0,16-0,07-0,10-0,14-0,16-0,22-0,16-0,16-0,18-$

1) Contribuição número 1256 do Departamento de Zoologia, Universidade Federal do Paraná.

2) Departamento de Zoologia, Universidade Federal do Paraná. Caixa Postal 19020, 81531-990 Curitiba, Paraná, Brasil. E-mail: zbuzzi@bio.ufpr.br

Revta bras. Zool. 19 (2): $335-337,2002$ 
0,28 . Os artículos 3 e 4 são os de menor diâmetro e cilíndricos; o escapo e o antenômero apical, os mais longos, seguindo-se o sétimo; os últimos artículos um pouco achatados.

Pronoto cerca de 1,8 vezes mais largo que seu comprimento mediano $(3,42$ $\mathrm{x} 1,92)$; aba transparente, reticulada, com alguns pontos esparsos, mais abundantes aos lados; margem anterior largamente arredondada; com forte curvatura; superfície discal com curto sulco mediano, longitudinal, insconspícuo e com pontos finos, escassos e alguns pontos maiores, próximo à margem; posteriormente com mancha marron-escura, com chanfro látero-anterior; a projeção mediana posterior, com leve depressão a cada lado. Escutelo triangular, marron-escuro, pouco mais largo na base que seu comprimento $(0,6 \times 0,5)$. Pernas com o fêmur anterior pouco mais curto que o médio e posterior $(1,10 \times 1,20 \times 1,20)$ e tíbia mediana mais curta que a anterior e posterior $(0,96 \times 0,82 \times 0,96)$. Élitros cerca de 1,2 vezes mais longos que sua largura mediana; aba transparente, lisa, reticulada; látero-anteriormente projetados até próximo à metade do pronoto e dali para trás alargando-se até o meio e estreitando-se a seguir; ápice arredondado; superfície densamente pontuada, com grandes pontos, geralmente de diâmetro maior que as interestrias; destacam-se duas fileiras de pontos posteriores, paralelas à sutura e que atingem a mancha amarela dorsal que apresenta poucos pontos e uma terceira fileira de pontos de fundo marron que fica entre o anel e a aba, além da metade posterior; os pontos que delimitam a aba e o disco elitral com mancha marron em forma de U, com a abertura voltada para fora e visíveis ventralmente, ao longo da epipleura.

Material examinado. O holótipo e dois parátipos foram coletados pelo Dr. Koller, em 15.III.2000, na fazenda Mirante, da cidade Terenos, Mato Grosso do Sul, Brasil, situada entre os paralelos 20-22 e entre os meridianos 54-57 e encontram-se depositados na Coleção de Entomologia Pe. Jesus Santiago Moure, Departamento de Zoologia, Universidade Federal do Paraná (DZUP), Curitiba, Paraná, Brasil. Um terceiro parátipo foi coletado na nascente do Rio Forte, Mato Grosso, em 8.V.1991 por Júlio César Souza e depositado no museu da Universidade Federal de Mato Grosso, Cuiabá, estado de Mato Grosso, Brasil.

Discussão. Muitas espécies de Charidotis apresentam um anel dorsal marron ou preto com mancha amarela dorsal inclusa. C. circulus Boheman, 1855; C. circumducta (Boheman, 1855), C. mansueta (Boheman. 1855) e C. consentanea (Boheman, 1855) entram no primeiro grupo da chave para o gênero Charidotis proposta por SPAETH (1936) e que se caracteriza por ter a área mediana do clípeo curta e as linhas frontais separadas abruptamente das órbitas e unidas entre si longe da base das antenas. C. speculum (Boheman, 1855) e C. brevicollis Spaeth, 1936 apresentam anel preto, bastante estreitado e o escutelo amarelo e incluso na mancha amarela dorsal. C. cyclops Fabricius, 1801, C. exquisita (Boheman, 1862), C. laetabunda Spaeth, 1936, C. luteola Boheman, 1855, C. procincta Boheman, 1855, C. soror (Boheman, 1855) se distinguem pelo anel dorsal que varia no tamanho e cor, pontuação dos élitros e coloração ventral. Em todas as espécies o anel do élitro é contínuo com a mancha posterior do pronoto, que apresenta a margem anterior arredondada. O que caracteriza $C$. terenosensis são: a mancha posterior do pronoto apresenta na margem anterior dois chanfros, um a cada lado; os bordos do anel não são bem definidos e as manchas marrons no meio da mancha amarela dorsal. 


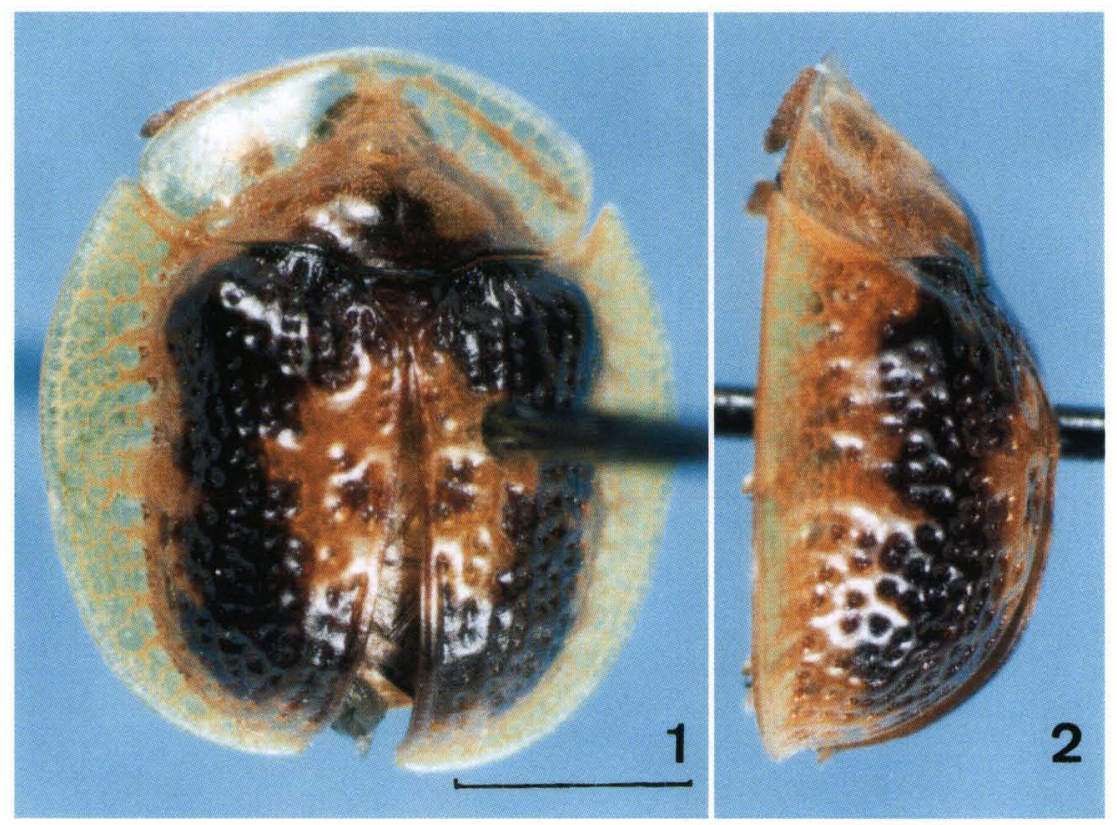

Figs 1-2. Charidotis terenosensis sp. n., holótipo. (1) Vista dorsal; (2) lateral. Escala $=1,75 \mathrm{~mm}$.

\section{REFERÊNCIAS BIBLIOGRÁFICAS}

BLACKWELDER, R.E. 1946. Checklist of the coleopterous insects of Mexico, Central America. The West Indies and south America. Bull. U.S. Nat. Mus. 185 (4): 551-763.

BOHEMAn, C. 1855. Monographia cassididarum. 3. Holmiae, 543p.

SPAETH, F. 1914. Coleopterorum Catalogus auspiciis et auxilio W. Junk editus a S. Schenkling. 62. Cassidinae. 182p. 1936. Bestimmungstabelle der Gattung Charidotis (Col., Chrys., Cassid.). Sborn. Ent. Odd. Nár. Mus. Praze 14: 66-99. 